\title{
Effects of spent mushroom compost meal on growth performance and meat characteristics of grower geese
}

\author{
Shen-Chang Chang ${ }^{1,2}$, Min-Jung Lin ${ }^{1,2}$, Yun-Peng Chao ${ }^{3,4}$, Chung-Jen Chiang ${ }^{5}$, Yu-Shine Jea ${ }^{2}$, \\ Tzu-Tai Lee ${ }^{1}$
}

\author{
${ }^{1}$ National Chung Hsing University, Department of Animal Science, Taichung, Taiwan. \\ ${ }^{2}$ Council of Agriculture, Livestock Research Institute, Changhua Animal Propagation Station, Changhua, Taiwan. \\ ${ }^{3}$ Feng Chia University, Department of Chemical Engineering, Taichung, Taiwan. \\ ${ }^{4}$ Asia University, Department of Health and Nutrition Biotechnology, Taichung, Taiwan. \\ ${ }^{5}$ China Medical University, Department of Medical Laboratory Science and Biotechnology, Taichung, Taiwan.
}

\begin{abstract}
The objective of this study was to determine the effect of spent mushroom compost (SMC) meal on the growth performance and meat characteristics of geese. The SMC extracts contained $2.49 \pm 0.62 \mathrm{mg}$ gallic acid equivalent $/ \mathrm{g}$ dry weight (DW) and $1.08 \pm 0.15 \mathrm{mg}$ quercetin equivalent/g DW of the total phenolic and flavonoid contents. A total of 120 White Roman geese, aged five weeks, were randomly distributed among 12 pens and fed a grower diet ad libitum during the growing period, with each pen containing five males and five females in a completely randomized design. Each treatment comprised three pens (total of 30 geese), including control (corn-soybean meal); supplementation with 5\% SMC meal (5\% SMC); supplementation with $10 \%$ SMC (10\% SMC); and supplementation with $15 \%$ SMC (15\% SMC), for eight weeks. The results revealed that the body weight of the $15 \%$ SMC group was significantly lower than that of the control group at the age of 12 weeks. There were no significant effects among the groups on feed conversion ratio or intake. The malondialdehyde content of the serum in the $15 \%$ SMC group was lower than that of the control group at week 12 . There were no significant effects among the groups for blood biochemical parameters in grower geese at week 12. The color values of meats in the SMC groups were higher than those obtained with control group. The flavor and acceptability score of meats in the 5\% SMC group were significantly higher than for the 15\% SMC and control group. Supplementation with SMC at 5\% in the diet has no adverse effects on the growth performance of grower geese. However, SMC meal at 5\% in the diet favorably affects sensory attributes (meat flavor and acceptability).
\end{abstract}

Key Words: antioxidant, meat sensory evaluation, white Roman goose

\section{Introduction}

The cost of raw materials for poultry feeding has significantly increased annually. Thus, finding alternative feeds has become an important task of the feed/food industry. The mushroom industry is experiencing a global development, and the spent mushroom compost (SMC) from mushroom growing is typically recycled agricultural waste products that could thus provide a low-cost feed to animals.

Currently, mushrooms are typically cultivated within a 3-D architectural structure inside air-conditioned facilities. Substrates commonly used in mushroom production include agricultural by-products, such as cereal straw (rice, wheat,

Received November 11, 2015 and accepted February 23, 2016.

Corresponding author: ttlee@dragon.nchu.edu.tw

http://dx.doi.org/10.1590/S1806-92902016000600001

Copyright (C) 2016 Sociedade Brasileira de Zootecnia. This is an Open Access article distributed under the terms of the Creative Commons Attribution License (http://creativecommons.org/licenses/by/4.0/), which permits unrestricted use, distribution, and reproduction in any medium, provided the original work is properly cited. corn, and barley), cotton, cobs, husks, and pulp (Chang and Miles, 1989), which undergo a process of mixing, hightemperature composting, pasteurization, inoculation with a pure mushroom culture, and incubation, prior to mushroom production. When the mushroom fruiting bodies mature and are ready for sale, the spent mushroom compost (SMC) is available as a by-product/waste (Herrero-Hernández et al., 2011; Tajbakhsh et al., 2008). At this stage, the compost is known as "spent mushroom compost" (SMC), and it also has nutritional components (Mullen and McMahon, 2001): approximately $73.6 \%$ neutral detergent fiber, $55.0 \%$ acid detergent fiber, $8.1 \%$ crude protein, $2.1 \%$ ether extract, 9.8\% non-fibrous carbohydrate, and $6.4 \%$ crude ash (Kim et al., 2007). Based on this composition, SMC has potential as a feed resource for livestock. Growing Hanwoo steers were supplemented with $50 \%$ of the microbially-fermented spent mushroom substrates of the ad libitum group, which resulted in a tendency of increased live weight gain from 8 to $12 \%$, as compared with the control group (Kim et al., 2012). Suwandyastuti and Bata (2012) indicated that spent mushroom rice straw compost could replace $75 \%$ fresh 
Napoer grass (DM) for male cattle. Kim et al. (2012) reported that about $660,000 \mathrm{t}$ of SMC (Pleurotus eryngii) were produced annually in Korea, while in Taiwan, at present, an increase of $130 \%$ means the annual production is about 80,000 metric tons of SMC.

In addition to nutrition composition, SMC is composed of fungal mycelia, extracellular enzymes (such as cellulase and xylanase) secreted from mushrooms for degradation of substrates, and unused lignocellulosic substrates (Kumaran et al., 1997; Ayala et al., 2011). Moreover, one of these, laccase, a kind of enzyme for a lignin-degrading enzyme system, was extracted from the spent mushroom compost in Pleurotus eryngii (Lim et al., 2013). Park et al. (2012a) showed that goats fed 15\% SMC for six weeks had significantly higher white blood cell and lymphocyte counts than the control group or goats fed $20 \%$ SMC. Park et al. (2012b) reported that elk fed $15 \%$ or $20 \%$ SMC had higher blood urea nitrogen and glucose concentrations than the control group.

Geese are herbivorous poultry that resist coarse foods and can grow well if fed good forage grass. Hollister et al. (1984) showed that when goslings were fed 20\% Kentucky blue grass and dehydrated alfalfa, the feed conversion was not significantly different from those of goslings fed a control (corn-soybean meal) diet; however, feed costs were reduced. To our knowledge, little information is presently available regarding the influence of SMC meal applied as poultry feed. Therefore, the objective of this study was to investigate the use of SMC meal as feed on the growth, antioxidant enzymes activity, and meat characteristics of grower geese.

\section{Material and Methods}

The spent mushroom compost (Pleurotus ostreatus (Jacq.exFr.) Kumm.) used in this study was provided by a mushroom producer in Nantou county, Taiwan. The fresh SMC was dried in a forced-air dryer at $50{ }^{\circ} \mathrm{C}$ for $24 \mathrm{~h}$ and then ground to a powder (approximately $2.5 \mathrm{~mm}$ in size) prior to its addition to the feed. The SMC extracts were added to $100 \%$ distilled water $(1: 10, \mathrm{w} / \mathrm{v})$ at $95{ }^{\circ} \mathrm{C}$ for $2 \mathrm{~h}$ after filtering (Advantec NO. 1, Tokyo, Japan). The filtrate was evaporated until dry under vacuum conditions. The lyophilized extracts were rehydrated and the concentration was adjusted to $1 \mathrm{mg} / \mathrm{mL}$ for subsequent analysis.

Total phenolic contents were determined using a Folin-Ciocalteu reagent according to the method described by Kujala et al. (2000). The Folin-Ciocalteu reagent was mixed evenly with SMC extracts before adding the $\mathrm{Na}_{2} \mathrm{CO}_{3}$ solution, and measured with a spectrophotometer at $\mathrm{OD}_{730}$.
Then, with the contents of the phenolic compounds of the extracts, one microgram of the gallic acid equivalent (GAE) was determined using an equation that was obtained from the standard gallic acid graph. The flavonoid content of SMC extracts was determined by following the colorimetric method (Chang et al., 2002). Briefly, $0.5 \mathrm{~mL}$ of SMC extracts in methanol were mixed with methanol, $10 \%$ aluminum chloride, and $1 \mathrm{M}$ potassium acetate, and left for $25 \mathrm{~min}$ at room temperature. The absorbance of the reaction mixture was measured at $\mathrm{OD}_{415}$ with a spectrophotometer, and the calibration curve was obtained by preparing quercetin solutions.

One hundred twenty White Roman geese aged five weeks were randomly distributed among 12 pens and fed a grower diet ad libitum during the growing period, with each pen containing five males and five females, arranged in a randomized complete design. Initially, each treatment comprised three pens, with 10 geese in each pen, including: control (corn-soybean meal), supplementation with 5\% SMC meal (5\% SMC); supplementation with $10 \%$ SMC (10\% SMC); and supplementation with $15 \%$ SMC (15\% SMC), for 8 weeks (from weeks 5 to 12). The care and use of all geese complied with the Regulations of Laboratory Animals and were approved by the Institutional Animal Use and Care Committee (IACUC) according to the Regulations of Laboratory Animals, Changhua Animal Propagation Station, Livestock Research Institute (CAPSLRI, located at $23^{\circ} 51^{\prime} \mathrm{N}$ and $120^{\circ} 33^{\prime} \mathrm{E}$ ), COA-LRI, Council of Agriculture, Taiwan. During the experimental period, the geese experienced a natural photoperiod and day length of 11.00 to $12.00 \mathrm{~h}$. The controlled-environment finishing house was $1.26 \mathrm{~m}^{2}$ per goose. The pen of the finishing house measured $3.95 \times 2.5 \mathrm{~m}\left(9.88 \mathrm{~m}^{2}\right)$. It contained a wire floor, one tank, and two water dispensers, and drinking water was provided ad libitum. The SMC contained $4.71 \% \mathrm{CP}$ and 2,627 kcal ME/kg, respectively. During the experimental period, the geese were fed a grower diet (Table 1), which was formulated to meet the nutrient requirements according to the NRC (1994), and the proximate composition was analyzed according to AOAC (1984).

At the end of 12 weeks, the performance of the geese was assessed by measuring the feed intake and body weight (BW); BW gain and feed conversion ratio were recorded. On the same day, 12 geese (six males and six females) from each group (four geese per pen) were randomly selected, blood samples were obtained from each goose by jugular venipuncture, and then they were killed by exsanguination. The blood samples were centrifuged at $2500 \times \mathrm{g}$ for $30 \mathrm{~min}$ at $4{ }^{\circ} \mathrm{C}$; the samples were then stored at $-20{ }^{\circ} \mathrm{C}$ until analysis. The samples for 
the carcass characteristics were individually weighed and harvested, and then expressed in grams per goose. The left breast muscles were frozen at $-20{ }^{\circ} \mathrm{C}$ for further meat characteristic evaluation.

First, the left breasts were weighed and cooked to an internal temperature of $80{ }^{\circ} \mathrm{C}$ in a digital thermostat water bath until the temperature of the meat center reached $71{ }^{\circ} \mathrm{C}$, after which the breasts were cooled for $30 \mathrm{~min}$ (AMSA, 1995). Each of the breasts was cut into six adjacent $1 \mathrm{~cm}$ (width) $\times 1 \mathrm{~cm}$ (thickness) $\times 3 \mathrm{~cm}$ (length) strips, parallel to the direction of the muscle fibers (Gentry et al., 2002). Each strip was sheared once, and the mean was calculated for each breast. Samples were sheared perpendicular to the muscle fibers using a Stable Micro Systems TA-XT-Plus Texture Analyzer (Stable Micro Systems, UK). Cooking loss was reported as a percentage and calculated as (initial weight - final weight) $/$ (initial weight) $\times 100 \%$. For sensory evaluation, the breast meat testing was performed by sensory panelists in triplicate on each sample. A trained tenmember panel consisting of researchers from the Division of Animal Products Procession, Livestock Research Institute, Council of Agriculture in Taiwan, was used to evaluate

Table 1 - Ingredients and nutrient compositions of the experimental $\operatorname{diets}^{1}$ (as-fed basis)

\begin{tabular}{|c|c|c|c|c|}
\hline Ingredient & Control & $5 \% \mathrm{SMC}$ & $10 \% \mathrm{SMC}$ & $15 \% \mathrm{SMC}$ \\
\hline & \multicolumn{4}{|c|}{ - } \\
\hline Corn & 64.25 & 59.82 & 55.4 & 50.82 \\
\hline Soybean meal, 44\% & 21.5 & 21.9 & 22.3 & 22.8 \\
\hline Spent mushroom compost & 0 & 5.0 & 10.0 & 15.0 \\
\hline Wheat bran & 5.0 & 5.0 & 5.0 & 5.0 \\
\hline Cane molasses & 3.0 & 3.0 & 3.0 & 3.0 \\
\hline Salt & 0.3 & 0.3 & 0.3 & 0.3 \\
\hline Dicalcium phosphate & 0.8 & 0.79 & 0.78 & 0.77 \\
\hline Limestone, pulverized & 1.60 & 1.62 & 1.63 & 1.7 \\
\hline Choline chloride, $50 \%$ & 0.1 & 0.1 & 0.1 & 0.1 \\
\hline Lysine & 0 & 0.01 & 0.02 & 0.03 \\
\hline DL-methionine & 0.2 & 0.21 & 0.22 & 0.23 \\
\hline Rice hulls & 3.0 & 2.0 & 1.0 & 0 \\
\hline Vitamin premix ${ }^{2}$ & 0.1 & 0.1 & 0.1 & 0.1 \\
\hline Mineral premix ${ }^{3}$ & 0.15 & 0.15 & 0.15 & 0.15 \\
\hline Total & 100.0 & 100.0 & 100.0 & 100.0 \\
\hline \multicolumn{5}{|l|}{ Calculated values } \\
\hline Metabolizable energy, $\mathrm{kcal} / \mathrm{kg}$ & 2800 & 2800 & 2800 & 2800 \\
\hline Crude protein, $\%$ & 15.5 & 15.5 & 15.5 & 15.5 \\
\hline Calcium, $\%$ & 0.73 & 0.73 & 0.73 & 0.73 \\
\hline Phosphorus, \% & 0.64 & 0.64 & 0.64 & 0.64 \\
\hline
\end{tabular}

${ }^{1}$ Control: corn-soybean meal; $5 \%, 10 \%$, and $15 \%$ SMC: supplementing 5\%, 10\%, and $15 \%$ of spent mushroom compost (SMC) meal in the basal diet, respectively.

${ }^{2}$ Provided per kilogram of diet: vitamin A - 10,000 IU; vitamin D3 - 2,000 IU; vitamin $\mathrm{E}$ - $20 \mathrm{mg}$; vitamin $\mathrm{K} 3$ - $1.5 \mathrm{mg}$; vitamin B1 - $1.00 \mathrm{mg}$; vitamin B2 - 4.8 $\mathrm{mg}$; vitamin B6 - $3.00 \mathrm{mg}$; vitamin B12 - $16 \mu \mathrm{g}$; folic acid - $0.50 \mathrm{mg}$; calcium pantothenate $-10.0 \mathrm{mg}$; niacin $-25 \mathrm{mg}$; biotin $-2.00 \mathrm{mg}$.

${ }^{3}$ Provided per kilogram of diet: $\mathrm{Fe}\left(\mathrm{FeSO}_{4}\right)-120 \mathrm{mg} ; \mathrm{Cu}\left(\mathrm{CuSO}_{4} .5 \mathrm{H}_{2} \mathrm{O}\right)-22.5 \mathrm{mg}$; $\mathrm{Mn}\left(\mathrm{MnSO}_{4} \cdot \mathrm{H}_{2} \mathrm{O}\right)$ - $120 \mathrm{mg} ; \mathrm{Zn}(\mathrm{ZnO})$ - $75.0 \mathrm{mg}$; I (KI) - $1.275 \mathrm{mg} ; \mathrm{Co}\left(\mathrm{CoSO}_{4}\right)$ $0.375 \mathrm{mg}$; $\mathrm{Se}\left(\mathrm{Na}_{2} \mathrm{SeO}_{3}\right)-0.27 \mathrm{mg}$. the chicken patties. Panelists were trained according to a sensory evaluation procedure. Each breast was evaluated in terms of color, flavor, juiciness, tenderness, and overall acceptability. Breast samples were placed in a vacuum bag, and heated at $80{ }^{\circ} \mathrm{C}$ in a water bath for $25 \mathrm{~min}$, then cut into quarters (size is $5 \times 5 \times 3 \mathrm{~cm}$ ), and randomly served to the panelists. Each sample was coded with a randomly selected three-digit number. Sensory evaluations were performed under fluorescent lighting. Panelists were instructed to cleanse their palates between samples using warm water $\left(30^{\circ} \mathrm{C}\right)$. The flavor $(1=$ extremely undesirable, $6=$ slightly desirable, $10=$ extremely desirable), juiciness $(1=$ extremely dry, $6=$ slightly juicy, $10=$ extremely juicy), visual color $(1=$ extremely undesirable, $6=$ slightly desirable, $10=$ extremely desirable), and overall acceptability $(1=$ extremely undesirable, $6=$ slightly desirable, 10 = extremely desirable) of the cooked samples were evaluated using a 10-point descriptive scale. This analysis was conducted using the hedonic test, as described by Choi et al. (2010a).

The serum biochemical values of geese were measured using an automatic biochemical analyzer (Hitochi, 7150 auto-analyzer, Hitachi, Tokyo, Japan). A spectrophotometer was used to colorimetrically assay the activities of superoxide dismutase (SOD) and Trolox equivalent antioxidant capacity (TEAC) (Wheeler et al., 1990). The procedures were conducted with assay kits purchased from Cayman Chemical Co. (Ann Arbor, MI, USA). The malondialdehyde (MDA) level was detected with 2-thiobarbituric acid, and the change of absorbance at $\mathrm{OD}_{523}$ was monitored with a spectrophotometer. All samples were measured in triplicate, and at appropriate dilutions, to allow the activities of enzymes to achieve the linear range of standard curves. Antioxidative enzyme activities were expressed as unit (U) per milliliter of serum (Lee et al., 2012b).

The data of the variables collected were analyzed statistically using the general liner models procedure (GLM) of SAS software (Statistical Analysis System, version 9.0.1) following a random arrangement.

The mathematical model was:

$$
\mathrm{Y}_{i j}=\mu+\mathrm{T}_{i}+\varepsilon_{i j}
$$

where $\mathrm{Y}_{i j}=$ observed response of bird in a pen; $\mu$ = overall mean; $\mathrm{T}_{i}=$ fixed effect of SMC supplementation; and $\varepsilon_{i j}=$ residual error when pen $t$ was regarded as experimental unit t, $\varepsilon_{i j} \sim N\left(0, \sigma_{\varepsilon}^{2}\right)$. The mean values were compared between four SMC supplementations using the LSMEANS with the significance level of $\mathrm{P}<0.05$. 


\section{Results}

The proximate composition results showed that SMC has $48.6 \%$ dry matter, $16.6 \%$ crude protein, and $65.1 \%$ crude fiber, respectively. The SMC extracts contained $2.49 \pm 0.62 \mathrm{mg}$ gallic acid equivalent $/ \mathrm{g}$ DW and $1.08 \pm 0.15 \mathrm{mg}$ quercetin equivalent/g DW of total phenolics and flavonoid contents.

There was no significant effect between the control and $5 \%$ SMC group in body weight $(\mathrm{P}<0.05)$ (Table 2$)$. The body weight of the $15 \%$ SMC group was significantly lower than that of the control group at the age of 12

Table 2 - Effect of spent mushroom compost on growth performance in grower geese

\begin{tabular}{|c|c|c|c|c|c|}
\hline \multirow{2}{*}{ Item } & \multicolumn{4}{|c|}{ Treatment $^{1}$} & \multirow{2}{*}{ SEM } \\
\hline & Control & $5 \% \mathrm{SMC}$ & $10 \% \mathrm{SMC}$ & $15 \% \mathrm{SMC}$ & \\
\hline & \multicolumn{5}{|c|}{ Body weight, kg/bird } \\
\hline Initial (5 wk) & 2.19 & 2.30 & 2.19 & 2.14 & 0.049 \\
\hline $8 \mathrm{wk}$ & $4.14 \mathrm{ab}$ & $4.23 \mathrm{a}$ & $3.89 b$ & $3.89 b$ & 0.084 \\
\hline \multirow[t]{2}{*}{$12 \mathrm{wk}$} & $4.95 \mathrm{a}$ & $4.90 \mathrm{ab}$ & $4.62 \mathrm{ab}$ & $4.58 b$ & 0.085 \\
\hline & \multicolumn{5}{|c|}{ Feed intake, $\mathrm{kg}$ feed/bird } \\
\hline $5-8 w k$ & 7.35 & 7.21 & 7.42 & 7.40 & 0.140 \\
\hline \multirow[t]{2}{*}{$9-12 \mathrm{wk}$} & 6.84 & 7.01 & 7.51 & 7.81 & 0.322 \\
\hline & \multicolumn{5}{|c|}{ Feed conversion ratio, $\mathrm{kg}$ feed $/ \mathrm{kg}$ gain } \\
\hline $5-8 w k$ & 3.83 & 3.82 & 4.41 & 4.26 & 0.219 \\
\hline $9-12 \mathrm{wk}$ & 8.76 & 11.5 & 11.0 & 14.4 & 2.220 \\
\hline
\end{tabular}

${ }^{1}$ Results are given as the means of three pens for 10 geese in each pen. Control: corn-soybean meal; $5 \%, 10 \%$, and $15 \%$ SMC: supplementing $5 \%, 10 \%$, and $15 \%$ of spent mushroom compost (SMC) meal in the basal diet, respectively.

SEM - standard error of the mean.

a,b - means without the same letter within the same row under treatment differ significantly $(\mathrm{P}<0.05)$.

Table 3 - Effect of spent mushroom compost on serum antioxidant enzyme activities in grower geese at weeks 8 and 12

\begin{tabular}{lccccc}
\hline \multirow{5}{*}{ Item } & \multicolumn{5}{c}{ Treatment $^{1}$} \\
\cline { 2 - 4 } & Control & $5 \% \mathrm{SMC}$ & $10 \% \mathrm{SMC}$ & $15 \% \mathrm{SMC}$ & \\
\hline \multicolumn{5}{c}{$\mathrm{SOD}, \mathrm{U} / \mathrm{mL}$} \\
$8 \mathrm{wk}$ & 49.4 & 54.2 & 54.2 & 50.2 & 2.494 \\
$12 \mathrm{wk}$ & 53.3 & 51.8 & 47.5 & 47.6 & 4.569 \\
& \multicolumn{5}{c}{$\mathrm{TEAC}, \mathrm{U} / \mathrm{mL}$} \\
$8 \mathrm{wk}$ & 0.45 & 0.43 & 0.45 & 0.35 & 0.035 \\
$12 \mathrm{wk}$ & 0.51 & 0.49 & 0.49 & 0.45 & 0.021 \\
& \multicolumn{5}{c}{$\mathrm{MDA}, \mathrm{U} / \mathrm{mL}$} \\
$8 \mathrm{wk}$ & 8.04 & 7.21 & 7.35 & 8.76 & 1.403 \\
$12 \mathrm{wk}$ & $8.20 \mathrm{a}$ & $6.00 \mathrm{ab}$ & $6.98 \mathrm{ab}$ & $4.34 \mathrm{~b}$ & 1.004 \\
\hline
\end{tabular}

${ }^{1}$ Results are given as the means of three pens for four geese in each pen. Control: corn-soybean meal; $5 \%, 10 \%$, and $15 \%$ SMC: supplementing $5 \%, 10 \%$, and $15 \%$ of spent mushroom compost (SMC) meal in the basal diet, respectively.

SEM - standard error of the mean.

SOD - superoxide dismutase; TEAC - trolox equivalent antioxidant capacity; MDA malondialdehyde.

$\mathrm{a}, \mathrm{b}$ - means within the same rows in the same period but without the same letter are significantly different $(\mathrm{P}<0.05)$. weeks $(\mathrm{P}<0.05)$. There were no significant differences among the groups for feed conversion ratio or intake $(\mathrm{P}>0.05)$.

There were no significant effects among the groups for serum SOD and TEAC at weeks 8 and $12(\mathrm{P}>0.05)$. Serum MDA content in the $15 \%$ SMC group was lower than that of control group at week $12(\mathrm{P}<0.05$; Table 3$)$. There were no differences between control and 5\% SMC group for serum MDA at 8 and 12 weeks. The results for the effects of SMC on blood biochemical parameters in grower geese at week 12 reveal no significant effects between the control and SMC groups regarding the blood biochemical parameters in grower geese at week 12 ( $\mathrm{P}>0.05$; Table 4).

There were no significant effects between control and SMC groups for carcass variables and meat characteristics of grower geese $(\mathrm{P}>0.05$; Table 5$)$. The color of the meats in the SMC groups had a higher score than that of control group $(\mathrm{P}<0.05)$. The flavor and acceptability scores of meats in the 5\% SMC group were significantly higher than those of control and $15 \%$ SMC groups $(\mathrm{P}<0.05$; Table 6$)$.

Table 4 - Effect of spent mushroom compost on blood biochemical parameters in grower geese at week 12

\begin{tabular}{|c|c|c|c|c|c|}
\hline \multirow{2}{*}{ Item } & \multicolumn{4}{|c|}{ Treatment $^{1}$} & \multirow{2}{*}{ SEM } \\
\hline & Control & $5 \% \mathrm{SMC}$ & $10 \% \mathrm{SMC}$ & $15 \% \mathrm{SMC}$ & \\
\hline $\mathrm{WBC}, 10^{3} / \mu \mathrm{L}$ & 239 & 254 & 219 & 242 & 11.59 \\
\hline $\mathrm{RBC}, 10^{6} / \mu \mathrm{L}$ & 1.68 & 2.01 & 1.74 & 1.87 & 0.117 \\
\hline $\mathrm{HB}, \mathrm{g} / \mathrm{dL}$ & 10.8 & 12.2 & 10.9 & 11.4 & 0.436 \\
\hline HТ, $\%$ & 32.8 & 36.6 & 33.0 & 34.2 & 1.213 \\
\hline MCV, fl & 201 & 183 & 195 & 184 & 10.73 \\
\hline $\mathrm{MCH}, \mathrm{pg}$ & 66.5 & 60.8 & 63.4 & 61.2 & 3.418 \\
\hline $\mathrm{MCHC}, \mathrm{g} / \mathrm{dL}$ & 33.0 & 33.3 & 32.7 & 33.34 & 0.314 \\
\hline PLT, $10^{3} / \mu \mathrm{L}$ & 25.0 & 34.8 & 26.0 & 26.5 & 4.374 \\
\hline GLU, mg/dL & 142 & 135 & 160 & 144 & 6.947 \\
\hline BUN, mg/dL & 4.00 & 4.17 & 4.50 & 4.33 & 0.276 \\
\hline $\mathrm{UA}, \mathrm{mg} / \mathrm{dL}$ & 2.32 & 2.05 & 2.03 & 1.98 & 0.265 \\
\hline $\mathrm{TP}, \mathrm{g} / \mathrm{dL}$ & 5.83 & 5.87 & 6.20 & 6.92 & 0.456 \\
\hline ALB, g/dL & 2.67 & 2.68 & 2.77 & 2.97 & 0.162 \\
\hline $\mathrm{GLO}, \mathrm{g} / \mathrm{dL}$ & 3.17 & 3.18 & 3.43 & 3.95 & 0.296 \\
\hline $\mathrm{A} / \mathrm{G}$ & 0.84 & 0.84 & 0.81 & 0.78 & 0.018 \\
\hline $\mathrm{TG}, \mathrm{mg} / \mathrm{dL}$ & 155 & 139 & 137 & 130 & 15.01 \\
\hline $\mathrm{TC}, \mathrm{mg} / \mathrm{dL}$ & 207 & 215 & 208 & 224 & 13.29 \\
\hline $\mathrm{HDL}, \mathrm{mg} / \mathrm{dL}$ & 106 & 112 & 106 & 122 & 7.624 \\
\hline $\mathrm{LDL}, \mathrm{mg} / \mathrm{dL}$ & 72.0 & 79.0 & 81.8 & 81.0 & 6.746 \\
\hline
\end{tabular}

${ }^{1}$ Results are given as the means of three pens for four geese in each pen. Control: corn-soybean meal; $5 \%, 10 \%$, and $15 \%$ SMC: supplementing $5 \%, 10 \%$, and $15 \%$ of spent mushroom compost (SMC) meal in the basal diet, respectively.

SEM - standard error of the mean.

WBC - white blood cell; RBC - erythrocyte; HB - hemoglobin; HT - hematocrit; $\mathrm{MCV}$ - mean corpuscular volume (HT/RBC); $\mathrm{MCH}$ - mean corpuscular hemoglobin (HB/RBC); MCHC - mean corpuscular hemoglobin concentration (HB/HT); PLT platelet, GLU - glucose; BUN - blood urea nitrogen; UA - uric acid; TP - total protein; ALB - albumin; GLO - globulin; A/G - ALB/GLO; TG - triglycerides; TC - total cholesterol; HDL - high-density lipoprotein; LDL - low-density lipoprotein. 
Table 5 - Effect of spent mushroom compost on carcass performances and meat characteristic in grower geese at week 12

\begin{tabular}{lccccc}
\hline \multirow{2}{*}{ Item } & \multicolumn{5}{c}{ Treatment $^{1}$} \\
\cline { 2 - 5 } & Control & $5 \%$ SMC & $10 \%$ SMC & 15\% SMC & \\
\hline Carcass & & & & & \\
Breast weight, \%LW & 17.7 & 17.40 & 16.8 & 16.4 & 0.86 \\
Legs weight, \%LW & 13.5 & 13.8 & 13.4 & 13.7 & 0.33 \\
Head and neck & 10.4 & 11.0 & 10.8 & 9.96 & 0.56 \\
weight, \%LW & & & & & \\
Back weight, \%LW & 14.7 & 15.9 & 14.9 & 16.0 & 0.59 \\
Paw weight, \%LW & 3.07 & 3.26 & 3.08 & 3.07 & 0.18 \\
Abdominal fat & 2.27 & 2.21 & 2.39 & 2.21 & 0.28 \\
pad weight, \%LW & & & & & \\
Liver weight, \%LW & 1.49 & 1.59 & 1.49 & 1.45 & 0.10 \\
Gizzard weight, \%LW & 4.27 & 3.80 & 3.93 & 4.10 & 0.34 \\
Intestinal weight, \%LW & 3.57 & 4.22 & 4.04 & 3.94 & 0.29 \\
Meat characteristic & & & & & \\
Cooking loss, \% & 32.9 & 30.5 & 30.6 & 29.3 & 0.881 \\
Shear value, kg/cm ${ }^{2}$ & 7.68 & 7.13 & 8.17 & 8.35 & 0.793 \\
\hline
\end{tabular}

${ }^{1}$ Results are given as the means of three pens for four geese in each pen. Control: corn-soybean meal; $5 \%, 10 \%$, and $15 \%$ SMC: supplementing $5 \%, 10 \%$, and $15 \%$ of spent mushroom compost (SMC) meal in the basal diet, respectively.

SEM - standard error of the mean.

LW - live weight.

Table 6 - Effect of spent mushroom compost on sensory evaluation in grower geese at week 12

\begin{tabular}{lccccc}
\hline \multirow{2}{*}{ Item } & \multicolumn{4}{c}{ Treatment $^{1}$} & \multirow{2}{*}{ SEM } \\
\cline { 2 - 5 } & Control & $5 \%$ SMC & $10 \%$ SMC & $15 \%$ SMC & \\
\hline Flavor & $5.25 \mathrm{~b}$ & $6.94 \mathrm{a}$ & $5.82 \mathrm{ab}$ & $5.19 \mathrm{~b}$ & 0.409 \\
Juiciness & $6.63 \mathrm{a}$ & $6.13 \mathrm{ab}$ & $7.06 \mathrm{a}$ & $5.25 \mathrm{~b}$ & 0.341 \\
Color & $4.38 \mathrm{~b}$ & $6.69 \mathrm{a}$ & $6.06 \mathrm{a}$ & $6.44 \mathrm{a}$ & 0.468 \\
Acceptability & $4.81 \mathrm{c}$ & $7.81 \mathrm{a}$ & $6.88 \mathrm{ab}$ & $6.32 \mathrm{~b}$ & 0.502 \\
\hline
\end{tabular}

${ }^{1}$ Results are given as the means of three pens for two geese in each pen. Control: corn-soybean meal; $5 \%, 10 \%$, and $15 \%$ SMC: supplementing $5 \%, 10 \%$, and $15 \%$ of spent mushroom compost (SMC) meal in the basal diet, respectively.

SEM - standard error of the mean.

a,b,c - means without the same letters within the same row under treatment differ significantly $(\mathrm{P}<0.05)$

\section{Discussion}

The body weight of the $15 \%$ SMC group was significantly lower than that of control group at the age of 5-12 weeks in grower geese, which may suggest that the increased coarse fiber in feed can result in reduced nutrient digestion rate. Foluke et al. (2014) indicated that $75 \%$ or $100 \%$ SMC replaced with wheat bran in poultry diet led to a significantly lower body weight in starter and finisher phases, as compared with $50 \%$ SMC and control groups. The authors suggest that the increased SMC replacement reduced the protein surface digestion rate. Hsu et al. (2000) pointed out that feed with a high content of crude fiber (16\%) would reduce the residence time of feed in the stomach and intestines and increase the volume of the stomach and intestines in geese. This may also illustrate why the $15 \%$ SMC group had a lower trend for feed conversion ratio than the 5\% SMC group at 9-12 weeks (14.4 vs. $11.5 \mathrm{~kg}$ feed $/ \mathrm{kg}$ gain).

Because free radicals attack the phospholipids of cell membranes, which contain large amounts of unsaturated fatty substances, they may cause lipid peroxidation, be oxidized into lipid peroxide, and finally, be converted to secondary metabolites (such as MDA). The intake of natural phytogenic components (e.g., resveratrol and phenolic components) could effectively reduce the amount of animal serum MDA (Sahin et al., 2010; Lee et al., 2012a). Spent mushroom compost has phytogenic components, such as phenolic compounds and flavonoids, which could significantly protect cells from the damage of free radicals and improve antioxidant capacity (Tuzcu et al., 2008); hence, it could effectively decrease the serum MDA content for the higher SMC-replaced group in this study.

The blood biochemical parameters showed no significant difference when broilers consumed a diet supplemented with $3 \%$ or $5 \%$ of dietary garlic powder (Choi et al., 2010b; Elagib et al., 2013). Moreover, broilers fed a dietary mixture of medicinal herb extracts (consisting of green tea, garlic, chicory, and cinnamon) showed no influence in the composition of raw thigh meat when compared with control group (Shirzadegan and Falahpour, 2014). Fletcher (2002) showed that the values of shear force increased with age due to an increase in the hardness of connective tissue and in collagen cross-linking, but not in the formula of the feed. This illustrates that there is no significant difference between geese fed SMC and control group in terms of chest carcass performance and meat characteristics.

Kim et al. (2009) pointed out that sensory panelists recorded greater hardness and flavor scores for birds receiving dietary supplementation of $2.0 \%$ and $4.0 \%$ garlic bulb and husk. Sahoo et al. (2013) used a diet supplemented with $0.05 \%$ or $0.1 \%$ of an herbal mixture (Allium sativum, Commiphora mukul, and Trigonella foenum graecum) and obtained a lean meat product with increased overall acceptability, as compared with the meat in the control group. In this study, panelists recorded higher flavor levels in meat from geese fed 5\% SMC than from the control group. The score for color of meats in the SMC groups was also higher than that of control group. In conclusion, this could suggest better customer acceptability in subsequent sales of products for geese given and 5\% SMC in their diet. The $5 \%$ corn replaced with 5\% SMC meal provides better meat sensory attributes for grower geese; thus, SMC could be utilized in geese diets, and as it is a local resource, it would reduce costs. This strategy can help solve an environmental issue that could result from the accumulation of agricultural wastes. 


\section{Conclusions}

Spent mushroom compost can be supplemented at $5 \%$ in the feed without adversely influencing growth performance or meat characteristics. The level of 5\% spent mushroom compost provides better meat sensory attributes for grower geese. Spent mushroom compost can be utilized in geese diets, and as it is a local resource, it may reduce costs.

\section{Acknowledgments}

The authors thank Dr. Yang-Kwang Fan, at the Department of Animal Science, National Chung Hsing University, Taiwan, for his guidance.

\section{References}

AOAC - Association of Official Analytical Chemists. 1984. Official methods of analysis. 14th ed. Association of Official Analytical Chemists, Washington, DC.

AMSA - American Meat Science Association. 1995. Research guidelines for cookery, sensory evaluation, and instrumental tenderness measurements of fresh meat. Chicago.

Ayala, M.; González-Muñoz, S. S.; Pinos-Rodríguez, J. M.; Vázquez, C.; Meneses, M.; Loera, O. and Mendoza, G. D. 2011. Fibrolytic potential of spent compost of the mushroom Agaricus bisporus to degrade forages for ruminants. African Journal of Microbiology Research 5:241-249.

Chang, S. T. and Miles, P. G. 1989. Edible mushrooms and their cultivation. CRC Press, Florida.

Chang, C.; Yang, M.; Wen, H. and Chern, J. 2002. Estimated of total flavonoid content in propolis by two complementary colorimetric methods. Journal of Food and Drug Analysis 10:178-182.

Choi, Y. S.; Choi, J. H.; Han, D. J.; Kim, H. Y.; Lee, M. A.; Jeong, J. Y.; Chung, H. J. and Kim, C. J. 2010a. Effects of replacing pork back fat with vegetable oils and rice bran fiber on the quality of reduced-fat frankfurters. Meat Science 84:557-563.

Choi, I. H.; Park, W. Y. and Kim, Y. J. 2010b. Effects of dietary garlic power and $\alpha$-tocopherol supplementation on performance, serum cholesterol levels, and meat quality of chicken. Poultry Science 89:1724-1731.

Elagib, H. A. A.; El-Amin, W. I. A.; Elamin, K. M. and Malik, H. E. E. 2013. Effect of dietary garlic (Allium sativum) supplementation as feed additive on broiler performance and blood profile. Journal of Animal Science Advances 3:58-64.

Fletcher, D. L. 2002. Poultry meat quality. Worlds Poultry Science Journal 58:131-145.

Foluke, A.; Olutayo, A. and Olufemi, A. 2014. Assessing spent mushroom substrate as a replacement to wheat bran in the diet of broilers. American International Journal of Contemporary Research 4:178-183.

Gentry, J. G.; McGlone, J. J.; Miller, M. F. and Blanton, Jr, J. R. 2002. Diverse birth and rearing environment effects on pig growth and meat quality. Journal of Animal Science 80:1707-1715.

Herrero-Hernández, E.; Andrades, M. S.; Rodríguez-Cruz, M. S. and Sánchez-Martín, M. J. 2011. Effect of spent mushroom substrate applied to vineyard soil on the behaviour of copper-based fungicide residues. Journal of Environmental Management 92:1849-1857.
Hollister, A. G.; Nakaue, H. S. and Arscott, G. H. 1984. Studies with confinement-reared goslings: 1. Effects of feeding high levels of dehydrated alfalfa and kentucky blue grass to growing goslings. Poultry Science 63:532-537.

Hsu, J. C.; Chen, L. I. and Yu, B. 2000. Effects of levels of crude fiber on growth performances and intestinal carbohydrases of domestic goslings. Asian-Australasian Journal of Animal Sciences 13:1450-1454.

Kim, Y. I.; Bae, J. S.; Jung, S. H.; Ahn, M. H. and Kwak, W. S. 2007. Yield and physicochemical characteristics of spent mushroom (Pleurotus ryngii, Pleurotus osteratus and Ammulina velutipes) substrates according to mushroom species and cultivation types. Journal of Animal Science and Technology 49:79-88.

Kim, Y. I.; Lee, Y. H.; Kim, K. H.; Oh, Y. K.; Moon, Y. H. and Kwak, W. S. 2012. Effects of supplementing microbially-fermented spent mushroom substrates on growth performance and carcass characteristics of Hanwoo steers (a field study). Asian-Australasian Journal of Animal Sciences 25:1575-1581.

Kim, Y. J.; Jin, S. K. and Yang, H. S. 2009. Effect of dietary garlic bulb and husk on the physicochemical properties of chicken meat. Poultry Science 88:398-405.

Kujala, T. S.; Loponen, J. M.; Klika, K. D. and Pihlaja, K. 2000. Phenolics and betacyanins in red beetroot (Beta vulgaris) root: distribution and effect of cold storage on the content of total phenolics and three individual compounds. Journal of Agricultural and Food Chemistry 48:5338-5342.

Kumaran, S.; Sastry, C. A. and Vikineswary, S. 1997. Laccase, cellulase and xylanase activities during growth of Pleurotus sajor-caju on sago hampas. World Journal of Microbiology and Biotechnology 13:43-49.

Lee, T. T.; Chen, C. L.; Wang, C. C. and Yu, B. 2012a. Growth performance and antioxidant capacity of broilers supplemented with Echinacea purpurea L. in the diet. Journal of Applied Poultry Research 21:484-491.

Lee, T. T.; Ciou, J. Y.; Chiang, C. J.; Chao, Y. P. and Yu, B. 2012 b. Effect of Pleurotus eryngii stalk residue on the oxidative status and meat quality of broiler chickens. Journal of Agricultural and Food Chemistry 60:11157-11163.

Lim, S. H.; Lee, Y. H. and Kang, H. W. 2013. Efficient recovery of lignocellulolytic enzymes of spent mushroom compost from oyster mushrooms, Pleurotus spp., and potential use in dye decolorization. Mycobiology 41:214-220.

Mullen, G. J. and McMahon, C. A. 2001. The effects of land spreading and soil incorporation of spent mushroom compost on Co Monaghan grassland soils. Irish Journal of Agricultural and Food Research 40:189-197.

NRC - National Research Council. 1994. Nutrient requirements of poultry. 9th rev. ed. National Academy Press, Washington, DC.

Park, J. H.; Yoon, S. H.; Kim, S. W.; Shin, D.; Jin, S.K.; Yang, B. S. and Cho, Y. M. 2012a. Hematological and serum biochemical parameters of Korean native goats fed with spent mushroom substrate. Asian Journal of Animal and Veterinary Advances 7:1139-1147.

Park, J. H.; Kim, S. W.; Do, Y. J.; Kim, H.; Ko, Y. G.; Yang, B. S. and Shin, D. 2012b. Spent mushroom substrate influences elk (Cervus elaphus canadensis) hematological and serum biochemical parameters. Asian-Australasian Journal of Animal Sciences 25:320-324.

Sahin, K.; Orhan, C.; Tuzcu, M.; Ali, S.; Sahin, N. and Hayirli, A. 2010. Epigallocatechin-3 gallate prevents lipid peroxidation and enhances antioxidant defense system via modulating hepatic nuclear transcription factors in heat-stressed quails. Poultry Science 89:2251-2258

Sahoo, T.; Tiwari, S. P.; Ravikanth, K.; Thakur, A. and Maini, S. 2013. A new polyherbal formulation for lean meat production in broilers. International Journal of Advanced Research 1:70-76. 
Shirzadegan, K. and Falahpour, P. 2014. The physicochemical properties and antioxidative potential of raw thigh meat from broilers fed a dietary medicinal herb extract mixture. Open Veterinary Journal 4:69-77.

Suwandyastuti, S. N. O. and Bata, M. 2012. Utilization of spent rice straw compost to substitute napier grass fed to cattle and its effect on rumen metabolism products. Animal Production 14:147-154.

Tajbakhsh, J.; Abdoli, M. A.; Mohammadi Goltapeh, E.; Alahdadi, I. and Malakouti, M. J. 2008. Recycling of spent mushroom compost using earthworms Eisenia foetida and Eisenia Andrei. Environmentalist 28:476-482.

Tuzcu, M.; Sahin, N.; Karatepe, M.; Cikim, G.; Kilinc, U. and Sahin, K. 2008. Epigallocatechin-3-gallate supplementation can improve antioxidant status in stressed quail. British Poultry Science 49:643-648.

Wheeler, C.R.; Salzman, J. A.; Elsayed, N. M.; Omaye, S. T. and Korte, D. W. Jr. 1990. Automated assays for superoxide dismutase, catalase, glutathione peroxidase, and glutathione reductase activity. Analytical Biochemistry 184:193-199. 